\title{
Sol-gel zinc oxide nanoparticles: advances in synthesis and applications
}

\author{
Parisa Shafiee $^{\text {a,*, }}$, Mehdi Reisi Nafchi ${ }^{\text {b }}$, Sara Eskandarinezhad ${ }^{\text {, }}$, Shirin Mahmoudi ${ }^{\text {, }}$ \\ Elahe Ahmadi ${ }^{\mathrm{e}}$ \\ ${ }^{a}$ Catalyst and Nano Material Research Laboratory (CNMRL), School of Chemical, Petroleum and Gas Engineering, Iran University of Science and \\ Technology, Tehran, Iran \\ ${ }^{b}$ Advanced Materials Research Center, Department of Materials Engineering, Najafabad Branch, Islamic Azad University, Najafabad, Iran \\ ${ }^{c}$ Department of Mining and Metallurgy, Yazd University, Yazd, Iran \\ ${ }^{d}$ Semiconductor Department, Materials and Energy Research Center, Karaj, Iran \\ ${ }^{e}$ Department of Materials Engineering, Faculty of Engineering, Tarbiat Modares University, Tehran, Iran
}

\section{A B S T R A C T}

Zinc oxide nanoparticles $(\mathrm{ZnO})$ exhibit numerous characteristics such as biocompatibility, UV protection, antibacterial activity, high thermal conductivity, binding energy, and high refractive index that make them ideal candidates to be applied in a variety of products like solar cells, rubber, cosmetics, as well as medical and pharmaceutical products. Different strategies for $\mathrm{ZnO}$ nanoparticles' preparation have been applied: sol-gel method, co-precipitation method, etc. The sol-gel method is an economic and efficient chemical technique for the formation of nanoparticles (NPs) that has the ability to adjust the structural and optical features of the NPs. Nanostructures are generated from an aqueous solution including metallic and chemical precursors for modifying $\mathrm{pH}$ using either a gel or a sol as a yield. Among the various approaches, the sol-gel technique was revealed to be one of the desirable techniques for the synthesis of ZnO NPs. In this review, we explain some novel investigations about the synthesis of $\mathrm{ZnO}$ NPs via the sol-gel technique and applications of sol-gel $\mathrm{ZnO}$ NPs. Furthermore, we study recent sol-gel $\mathrm{ZnO} \mathrm{NPs}$, their significant characteristics, and their applications in biomedicals, antimicrobial packaging, drug delivery, semiconductors, biosensors, catalysts, photoelectron devices, and textiles.
KEYWORDS

Zinc oxide nanoparticles

Sol-gel synthesis

Applications of sol-gel zinc oxide

C 2021 The Authors. Published by Synsint Research Group.

\section{Introduction}

In recent years, nanoparticle applications have received considerable attention in the size range of 1 to $100 \mathrm{~nm}$ because of their new properties and have been the research subject of immense [1-4].
Nanoparticles are different from bulky materials in terms of properties [5-8]. ZnO nanoparticles' optical properties depend on the annealing morphology and temperature [9-12]. $\mathrm{ZnO}$ properties are usually related to its morphology and structure. Thus, controlling these properties is

\footnotetext{
* Corresponding author. E-mail address: Parisashafiee603@gmail.com (P. Shafiee)

Received 15 December 2021; Received in revised form 28 December 2021; Accepted 28 December 2021.

Peer review under responsibility of Synsint Research Group. This is an open access article under the CC BY license (https://creativecommons.org/licenses/by/4.0/). https://doi.org/10.53063/synsint.2021.1477
} 
one of the most important research in making $\mathrm{ZnO}$. To control the $\mathrm{ZnO}$ nanoparticle synthesis, monoethanolamine has been used as a structuredirecting factor of $\mathrm{ZnO}$ crystal formation. The $\mathrm{ZnO}$ crystalline structure owns a quartzite structure that has a single hexagonal cell with two lattice parameters $a$. In this hexagonal structure, four cations surround each anion at the corners that show the quadrilateral coordination and hence the covalent bond of $\mathrm{sp} 3$ [13-15].

Nanoparticles have a special place in almost every part of life such as the delivery of the controlled drug, electronic devices of sensors and photons [16, 17], electrocatalytic water decomposition, nanocomposites for storage of energy, and so on. Its potential applications are because of its electrical, optical, photochemical, and catalytic properties, and environmentally friendly nature of $\mathrm{ZnO}$ nanoparticles that have been widely investigated. $\mathrm{ZnO}$ nanoparticles have a wide application ranges such as biosensors, gas sensors, solar cells, ceramics, optical detectors, nanogenerators, active fillers for rubber, catalysts, and plastics, UV absorbers, cosmetics, and antiviral coatings, pigments of optical materials, optical and patriotic materials, optical probes, additives in high products of industrial and water and wastewater treatment [18-26]. In various articles, many scientists have reported the characterization and synthesis of nanostructures of $\mathrm{ZnO}$ in different ways including co-precipitation [27, 28], sol-gel technique, laser erosion, hydrothermal procedure, and coating deposition, electrochemical sediments, vapor chemical deposition, fabrication of green natural products, and so on. For the development of $\mathrm{ZnO}$ compositions, the sol-gel procedure has been interesting between these procedures. For example, the sol-gel procedure has been applied to formation of $\mathrm{Zn}_{1-\mathrm{x}} \mathrm{Zr}_{\mathrm{x}} \mathrm{O}$ (x $=0.00,0.01,0.03$ and 0.05) nanoparticles [29-31]. It is found that the dopant has significantly influenced the electrochemical implementation individually and simultaneously toward uric acid and superb yields have been achieved via the Zr-doped $\mathrm{ZnO}$ modified carbon paste electrode (MCPE) [32]. Additionally, Mourad et al. reported the formation of un-doped $\mathrm{ZnO}$ and $\mathrm{In}$-doped $\mathrm{ZnO}$ nanoparticles via sol-gel technique from 0 to $5 \mathrm{wt} \%$ of in values. Their morphological results indicated that the crystallite shapes were hexagonal and turned into cylindrical prismatic after doping [33]. In the case of the nanoparticles, it is known that the range and morphology of nanoparticles can be changed by changing the synthesis method and stoichiometric parameters. Like other nanostructures, $\mathrm{ZnO}$ has morphological properties, so the choice of synthesis technique has paramount importance in determining the features of the nanoparticle [34-37]. This study highlights the latest advancements specifically in numerous applications of sol-gel $\mathrm{ZnO}$ nanoparticles. Further, in the last 5 years ago, a lot of research about sol-gel $\mathrm{ZnO}$ nanoparticles have focused on their either properties and synthesis methods or applications but none of them has, to the best of the author's knowledge, reviewed both characteristics and applications in advance.

In this review paper, the steps of the sol-gel process are extensively investigated. Moreover, we briefly present a discussion summarizing studies on the synthesis of $\mathrm{ZnO}$ nanoparticles, their applications, and comparing the results. The various applications of $\mathrm{ZnO}$ sol-gel nanoparticles such as hydrogen production, biomedical, sensors, photovoltaics, and photocatalysis fields are extensively evaluated.

\section{The structure and properties of sol-gel $\mathrm{ZnO}$ nanoparticles}

\subsection{Formation of ZnO nanoparticles via sol-gel method}

The sol-gel method has been considered vitally beneficial for the fabrication of materials due to its economical nature, stability, reproducibility, and inexpensiveness. The sol-gel condition can be applied to fabricate various formations of materials including ceramics, thin-film coatings, and nanoparticles; making a large diversity of applications [38]. Among them, the synthesis of $\mathrm{ZnO}$ nanoparticles has attracted much attention from researchers using this procedure. For example, nanocrystalline $\mathrm{ZnO}$ was synthesized by Mahato et al. [39]. They hydrolyzed sarin to fabricate the surface-bound non-toxic phosphonate on the nano-zinc oxide surface. They also indicated the values of half-life and rate constant to be $0.16 \mathrm{~h}$ and $4.12 \mathrm{~h}^{-1}$ in the primary steps of the reaction and $1.9 \mathrm{~h}$ and $0.361 \mathrm{~h}^{-1}$ at the last steps of the reaction for the reaction of decontamination on nanocrystalline $\mathrm{ZnO}$. Nanocrystalline powder of $\mathrm{ZnO}$ using zinc 2-ethyl hexane ethylene glycol monomethyl $1 \%$ containing ether was prepared by Ristic et al. [40], with an aqueous solution of isopropanol and tetramethylammonium $\left(\left(\mathrm{CH}_{3}\right)_{4} \mathrm{NOH}\right)$ as precursors. TEM Results of nanoparticles demonstrated that the synthesized particles ranged in the size of 20-50 nm in this survey. Furthermore, the molding method of sol-gel was used to synthesize $\mathrm{ZnO}$ nanofibers [41, 42]. A simple method for the synthesis of $\mathrm{ZnO}$ nanotubes was reported by Yue et al. [43] with anodic aluminum oxide (AAO) of porous membranes under the condition of two-step anodizing in a solution of oxalic acid. The resulting nanotubes of $\mathrm{ZnO}$ were about $70 \mathrm{~nm}$ thick and $12 \mathrm{~nm}$ thick. Moreover, the sodium hydroxide and temperature role in the $\mathrm{ZnO}$ preparation nanoparticles were studied by Mayekar et al. [44]. Their study showed that the size of the particle was increased by raising the temperature and also with a rising concentration of sodium hydroxide $[45,46]$. Chemical synthesis is the most principle procedure and contains vast amounts of precursors and variable factors such as time, the concentration of reactants, temperature, etc. Changing these parameters causes diverse morphological varieties in the geometry size of nanoparticles. The results of the various chemical methods that have been used to synthesize zinc oxide nanoparticles are listed below [ 47 , 48].

1. The chemical reaction of zinc metal by alcohol: most alcohol types, including ethanol, propanol, or methanol are applied for synthesizing the chemical zinc oxide nanoparticles. The mixture of reaction is then socketed for 20 minutes and transferred to an autoclave. The suspension obtained to recover the product is centrifuged, washed, and totally dried in a vacuum. In an alcoholic environment, the growth of oxide particles is controllable and slow.

2. Vapor synthesis of transfer: the steam transfer process is the most common procedure for synthesizing zinc oxide nanostructures. In this condition, oxygen and zinc or vapors of the oxygen mixture are transferred and react by others, resulting in the zinc oxide nanostructures formation. There are many methods to produce zinc and vapor of oxygen. Another direct method includes heating powder of zinc under oxygen flow, but the ratio among zinc vapor oxygen pressure and pressure must be controlled to give the desired $\mathrm{ZnO}$ nanostructures. This has been shown that changes in this ratio lead to 
large variations in the morphology of the nanostructures (geometry and size) [49-51].

3. Hydrothermal procedure: this is an attractive procedure due to the low temperature of the process. Particle size control is very easy. This process has some benefits like using simple equipment, growth without catalysts, cost-effective, homogeneous yields, eco-friendly, and low risk compared to other fabrication methods. This procedure is attractive for plastic electronics and microelectronics because of its low reaction temperature. The size and morphology of particles can be justified under the hydrothermal condition via tuning the concentration of precursors, the temperature of the reaction, and time [52-55].

4. Sedimentation method: in this procedure, $\mathrm{ZnO}$ is generated via urea as a precursor and using zinc nitrate. In a common production, $0.5 \mathrm{M}$ $(4.735 \mathrm{~g})$ of zinc nitrate $\left(\mathrm{Zn}\left(\mathrm{NO}_{3}\right)_{2} \cdot 6 \mathrm{H}_{2} \mathrm{O}\right)$ is dissolved in $50 \mathrm{ml}$ of distilled water and the following is remained constant for 30 minutes for complete dissolution. The whole chemical reactions that happened in this condition are indicated in Fig. 1 [56-58].

\subsection{Characteristics of sol-gel $\mathrm{ZnO}$ nanoparticles}

$\mathrm{ZnO}$ is a harmless composite that has been used in different areas like solar cells, piezoelectric transducers, micro-sensors, catalysis, environmental sciences, and chemical photoelectrons. The fabrication of metal nanoparticles with specific properties is a new field of research that has attracted a lot of attention. Various methods have been proposed to synthesize these materials, including chemical vapor deposition, arc discharge, hydrogen plasma-metal reaction (HPMR), and laser chemical vapor pyrolysis (LaCVP), hydrothermal, microemulsion, and sol-gel. The characteristics of metal nanoparticles wieldy depend on their synthesis techniques. In general, formation methods of metal nanoparticles can be classified into two approaches: (1) physical routes like sputtering, ball mill, electron spray, beam electron evaporation, laser erosion, etc. (2) chemical-based routes like sol-gel technique, hydrothermal technique, microemulsion technique,

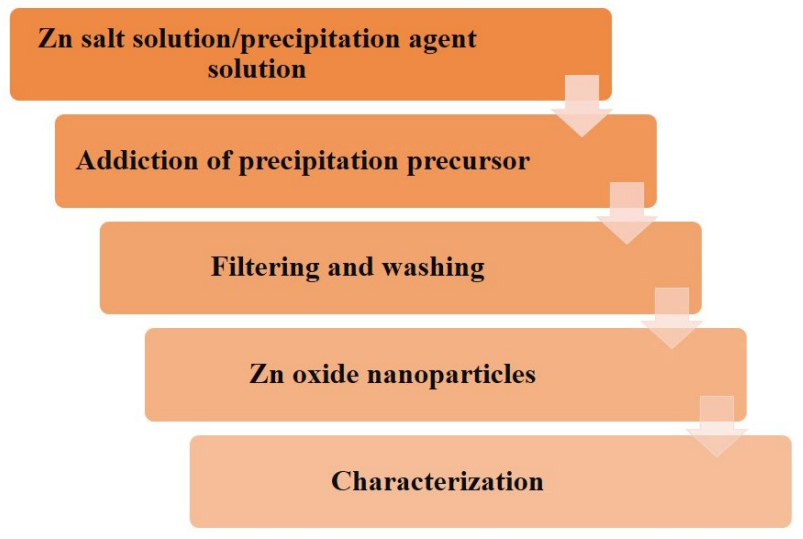

Fig. 1. Precipitation approach.

polyol method, chemical vapor deposition, simultaneous deposition method, etc. (see Fig. 2) [59, 60].

An economic and efficient chemical method for the production of nanoparticles is the sol-gel method with the ability to adjust the optical and structural features. This involves the process of the nanostructure production from an aqueous media including metal precursors, and chemicals for modification of $\mathrm{pH}$ using gel or sol as the intermediate outcome shown in Fig. 3 [61-63].

The method of sol-gel is the well-established synthesis method for the preparation of high-quality ZnO-NPs and also composites of mixed oxides. This procedure can easily control the surface of the material and properties of texture [64-66]. The sol-gel approach consists of five steps: thermal decomposition, polycondensation, hydrolysis, aging, and drying as shown in Fig. 4 [67, 68].

A summary of synthesized $\mathrm{ZnO}$ nanocomposites by sol-gel technique, synthesis conditions, and their properties are described in Table 1.

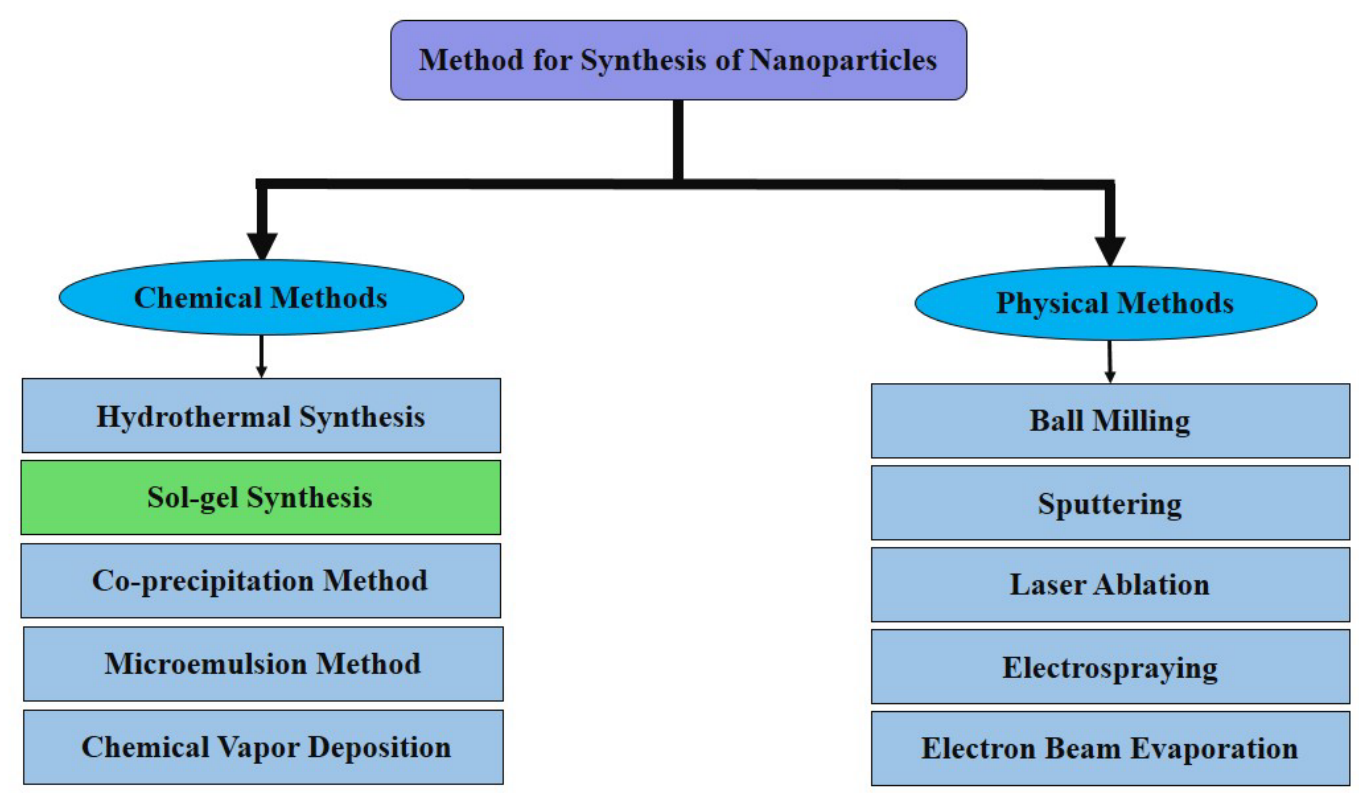

Fig. 2. Different methods of chemical and physical synthesis of ZnO-NPs. 
Table 1. A list of $\mathrm{ZnO}$ nanoparticles synthesized by sol-gel technique, their synthesis conditions, and properties.

\begin{tabular}{|c|c|c|c|}
\hline Precursors & Synthesis conditions & Characteristics & Ref. \\
\hline $\begin{array}{l}\text { Zinc 2-ethylhexanoate, } \\
\left(\mathrm{CH}_{3}\right)_{4} \mathrm{NOH} \text {, and isopropanol }\end{array}$ & $\begin{array}{l}\text { Stirring: at room temperature } \\
\text { Aging: } 30 \text { min- } 24 \mathrm{~h} \text {, drying: } 60^{\circ} \mathrm{C}\end{array}$ & Particles with a size range of $20-50 \mathrm{~nm}$ & {$[40,69]$} \\
\hline $\begin{array}{l}\text { Manganese acetate, ethanol, } \\
\text { sodium hydroxide, and zinc } \\
\text { acetate (applied as dopant) }\end{array}$ & $\begin{array}{l}\text { Heating in a water bath at } 60-65^{\circ} \mathrm{C} \text {, for } 2 \mathrm{~h} \\
\text { Centrifuge: at } 4000 \mathrm{rpm}, 20 \mathrm{~min}\end{array}$ & $\begin{array}{l}\text { Polycrystalline structures ranged from } 21 \mathrm{~nm} \text { to } 73 \mathrm{~nm} \text { were } \\
\text { synthesized, } \mathrm{ZnO}: \mathrm{Mn}^{2+} \text { with higher photocatalytic activity } \\
\text { than virgin } \mathrm{ZnO} \text { under visible light irradiation. }\end{array}$ & {$[70-72]$} \\
\hline $\begin{array}{l}\text { Ethanol, oxalic acid, and zinc } \\
\text { acetate dehydrate }\end{array}$ & $\begin{array}{l}\text { Stirring: } 60^{\circ} \mathrm{C} \\
\text { Drying: } 24 \mathrm{~h}, 80^{\circ} \mathrm{C} \\
\text { Calcination: } 500{ }^{\circ} \mathrm{C}\end{array}$ & $\begin{array}{l}\text { Randomly oriented aggregates of NPs and nanorods with } \\
\text { variable sizes. With an average crystallite size of } \sim 55 \mathrm{~nm} \\
\text { for decontamination of sarin were fabricated. }\end{array}$ & $\begin{array}{l}{[39,69,} \\
73]\end{array}$ \\
\hline $\begin{array}{l}\text { Ethanol, diethanolamine, and zinc } \\
\text { acetate }\end{array}$ & $\begin{array}{l}\text { Stirring: at room temperature } \\
\text { The ultrathin anodic aluminum oxide (AAO) membrane } \\
\text { was then immersed into the sol for } 30 \mathrm{~min} \text {. } \\
\text { Annealing: } 2 \mathrm{~h}, 500^{\circ} \mathrm{C}\end{array}$ & $\begin{array}{l}\mathrm{ZnO} \text { nanotubes with a diameter of } 70 \mathrm{~nm} \text { with the thickness } \\
\text { of } 12 \mathrm{~nm} \text { were fabricated in AAO membrane. }\end{array}$ & {$[43,74]$} \\
\hline $\begin{array}{l}\text { Methanol and zinc acetate } \\
\text { dihydrate }\end{array}$ & $\begin{array}{l}\text { Spin coating: } 20 \mathrm{~s}, 3000 \mathrm{rpm} \\
\text { Drying: } 10 \mathrm{~min}, 80^{\circ} \mathrm{C} \\
\text { Annealing: } 20 \mathrm{~min}, 500-575^{\circ} \mathrm{C}\end{array}$ & $\begin{array}{l}\text { Nanofilm with a thickness of } 160-230 \mathrm{~nm} \text { on the substrate of } \\
\text { Pyrex glass }\end{array}$ & {$[75,76]$} \\
\hline $\begin{array}{l}\text { Sodium hydroxide and zinc } \\
\text { chloride }\end{array}$ & $\begin{array}{l}\text { Stirring: } 80^{\circ} \mathrm{C} \\
\text { Drying: } 2 \mathrm{~h}, 80-100{ }^{\circ} \mathrm{C} \\
\mathrm{NaOH} \text { concentration: } 2-10 \mathrm{M}\end{array}$ & $\begin{array}{l}\text { Particles with } 20-350 \mathrm{~nm} \text { size were synthesized and formed } \\
\text { from spherical to rod-like structures. }\end{array}$ & {$[44,77]$} \\
\hline $\begin{array}{l}\text { 2-methoxy ethanol, } \\
\text { monoethanolamine, and zinc } \\
\text { acetate }\end{array}$ & $\begin{array}{l}\text { Spin coating: } 2000 \mathrm{rpm} \\
\text { Drying: } 10 \mathrm{~min}, 473 \text { or } 573 \mathrm{~K} \\
\text { Irradiation of dried film by KrF excimer } \\
\text { LASER ( } \lambda=248 \mathrm{~nm}, 22 \mathrm{~ns} \text { Full-Width Half Maximum) }\end{array}$ & $\mathrm{ZnO}$ nanofilms with a thickness of $35-60 \mathrm{~nm}$ were achieved. & {$[78-82]$} \\
\hline
\end{tabular}

The properties of sol-gel $\mathrm{ZnO}-\mathrm{NPs}$, due to the controlled stabilization of nanostructures, modulation of shape, and low temperature for processing, have been studied by many researchers. Recently, biomaterials have been used for synthesizing nanoparticles, especially metal oxidants and metal particles $[83,84]$.

\section{Sol-gel ZnO nanoparticle applications}

In the last decade, there has been considerable interest in NPs research, particularly in biomedical applications. The nanotechnology integration into the science of medicine has opened up new opportunities and created a better aspect of molecular biology. As a result, this is a

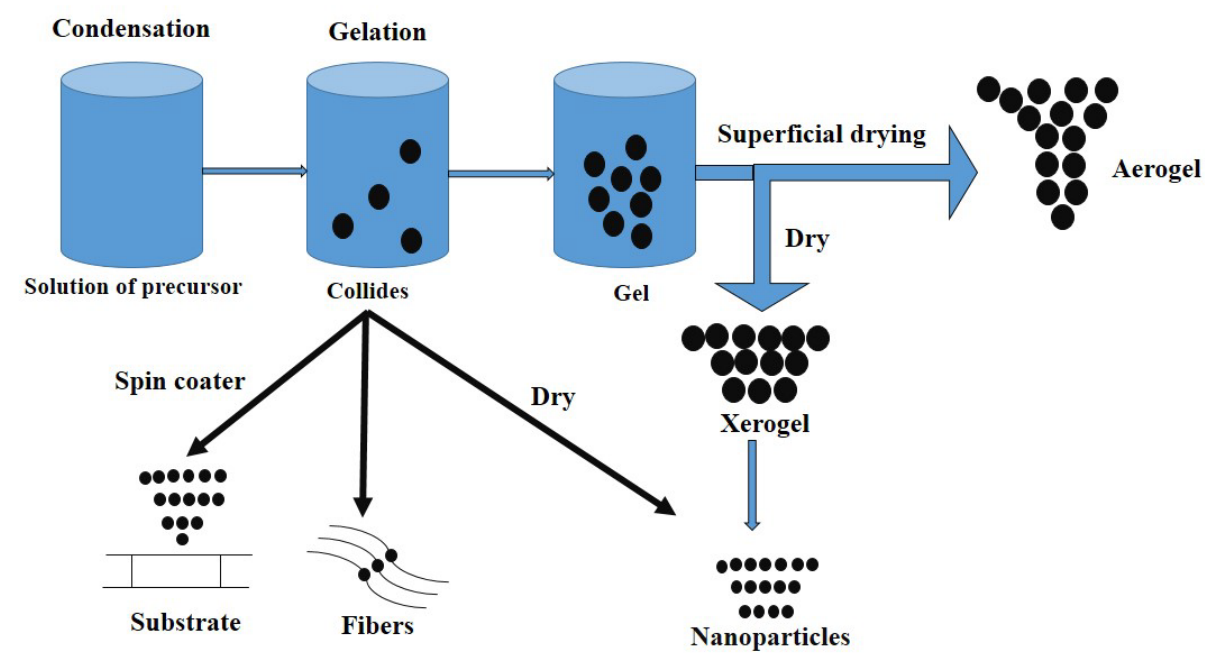

Fig. 3. Synthesis procedure of sol-gel for nanocomposite as an intermediate product. 


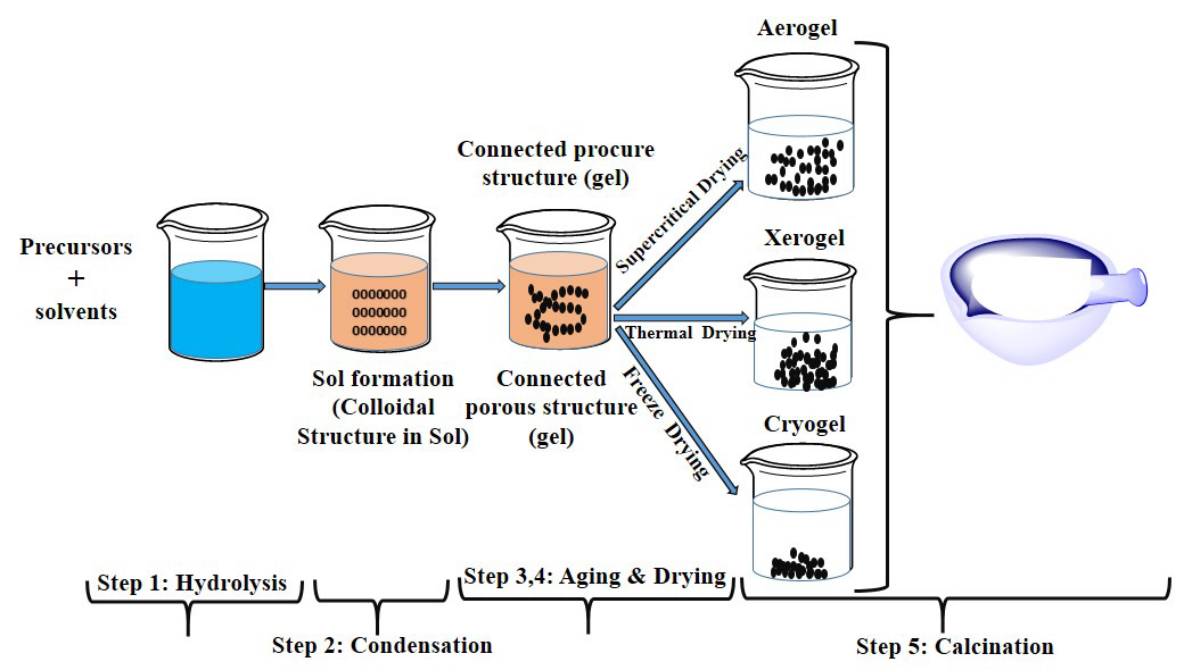

Fig. 4. Steps of synthesis action in the sol-gel process of $\mathrm{ZnO}-\mathrm{NPs}$.

potential for new approaches to treating diseases that were previously difficult to target because of size constraints [85-87]. Currently, this is a wide range of chemical synthesis techniques and materials which are being investigated for biomedical applications, as we reviewed some sorts of medical $\mathrm{ZnO}$ nanoparticles in this study. $\mathrm{ZnO}$ is also known as a valuable food additive and is widely used in pharmaceutical, cosmetic, and medical applications (Fig. 5). However, the inhalation of dust and fumes of $\mathrm{ZnO}$ should generally be avoided [88-92].

\subsection{Biomedical applications}

As there are several articles available on the various ZnO-NPs applications in medicine and biology, the current developments of ZnO-NPs for applications of biomedical: (a) drug and gene delivery, (b) anticancer, (c) anti-antigenic properties, (d) immunotherapy, (e) antimicrobial activity, (f) wound healing, (g) tissue engineering, (h) diabetes treatments, (i) bioimaging, and (j) biosensing are discussed in this session [93]. Fig. 6 demonstrates the diverse biomedical ZnO-NPs applications as described below [94-97]

Among the various metal nanoparticles, $\mathrm{ZnO}$-NPs have aroused lots of interest from biomedical researchers because of some factors, particularly tunable physicochemical features like surface, size, charge, morphology, etc. that can be useful for their pharmaceutical applications [98]. It should be noted that the effect of enhanced permeability and retention (EPR) can be used on target cancer cells by ZnO-NP through modification of their physicochemical properties. Besides, the appropriate cationic charge balance on the surfaces of ZnO-NPs improves their contact with the cell membrane, preventing quicker serum evacuation. Furthermore, ZnO-NPs with the right shape may be more easily recognized for biological applications. Then, modifying the physicochemical properties of ZnO-NPs may be an

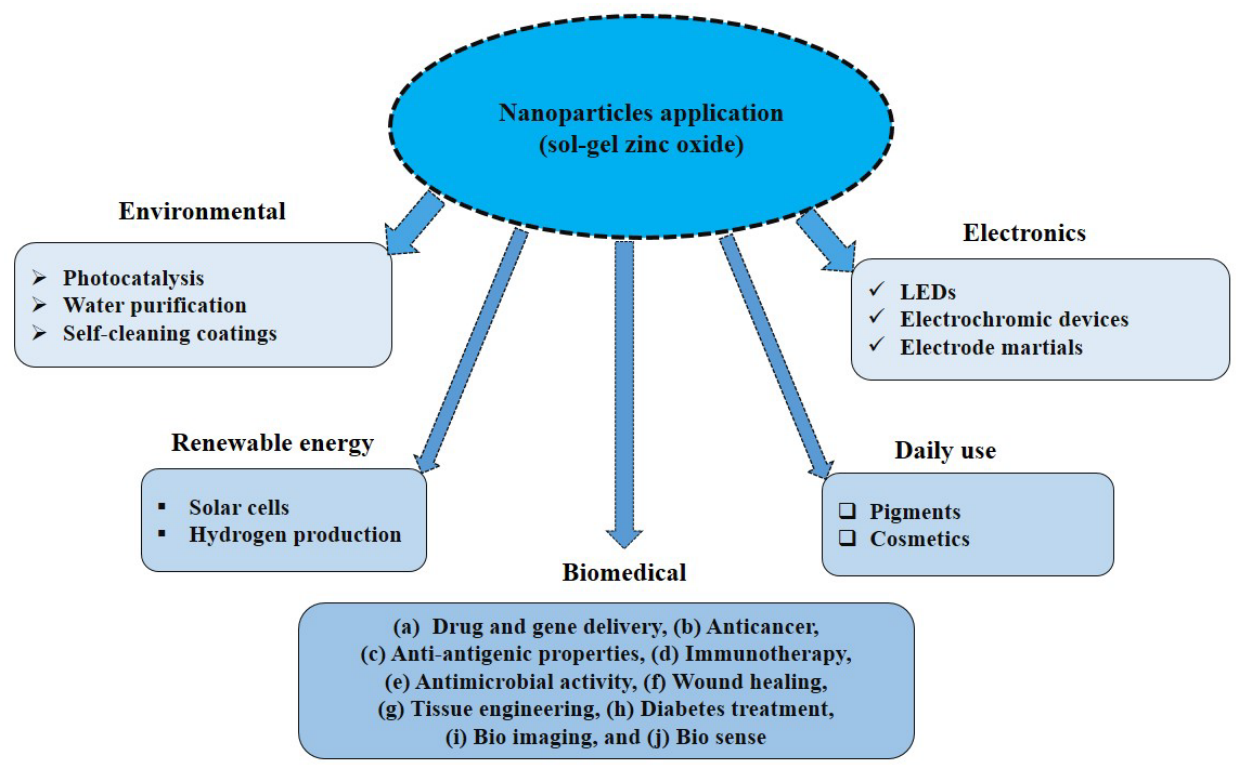

Fig. 5. Different applications of ZnO-NPs. 


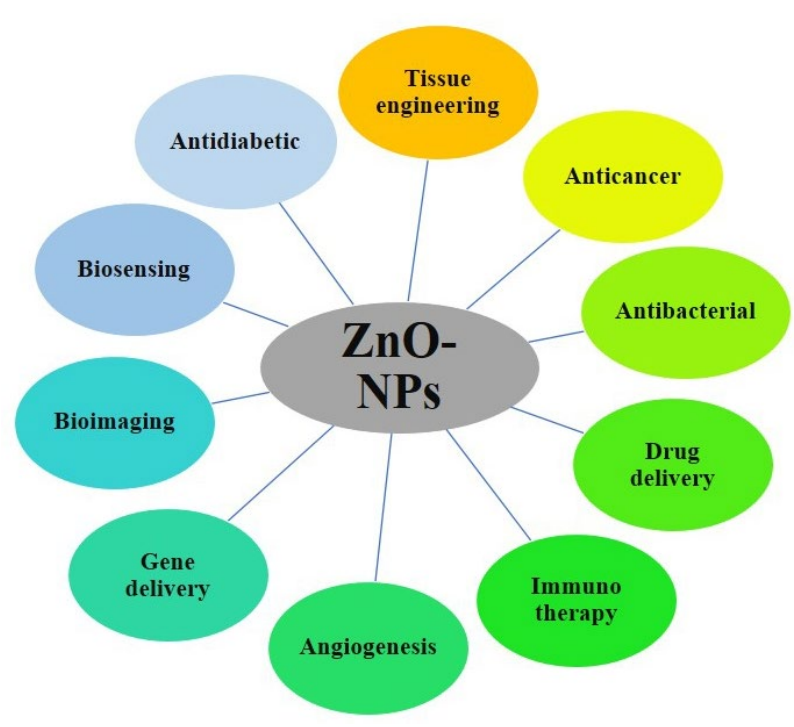

Fig. 6. Various $\mathrm{ZnO}-\mathrm{NP}$ applications in medicine and biology.

appropriate strategy to improve their biological impacts as a requirement for the dependence of the circumstances [95, 99-105].

\subsection{Antimicrobial packaging}

$\mathrm{ZnO}$ is tested as a candidate for drug agent in any micro-scale and formulations of nanoscale. The results have indicated that $\mathrm{ZnO}-\mathrm{NPs}$ have rendered drug activity that can be bigger than small particles. If the exact action mechanisms of the drug are not clearly understood, it is quickly realized that most of the cell swelling causes are reactive oxygen species (ROS) production. This is produced on the nanoparticle adsorption, particle surfaces, diffusion of zinc ion, and dysfunction of the unit membrane region. The antibacterial $\mathrm{ZnO}$-NPs mechanism has not yet been understood completely, and also the bacteria damage could happen in three ways indicated in Fig. 7 [106, 107].

High heat treatment of ZnO-NP has a significant effect on their medicinal activity, while subsequent temperature treatment results in less activity. The action mechanism of nanoparticles of $\mathrm{ZnO}$ is not good understood. Although it is predicted that oxide production may be the main subject of their activity, it has been shown that the particle binding on the surface of microorganisms due to electrical forces can be an evaluated mechanistic behavior. It is a drug of $\mathrm{ZnO}$ nanoparticles that can be done using chemical light analysis and oxygen analysis of electrodes. The surface unit of metal nanoparticles is ionic or high and

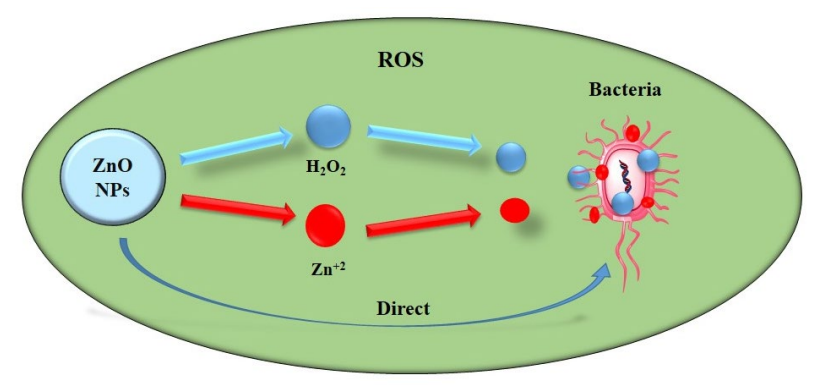

Fig. 7. The ZnO-NP mechanisms for antibacterial. must be prepared with extremely high surface areas, with various crystals and morphologies, having different edges/corners and different reactive locations of the surface. The $\mathrm{ZnO}-\mathrm{NPs}$ regional unit has been investigated in conjunction with the erosive regimes of the medical method. In addition, to the higher thermal effect on neoplasm erosion, nanoparticles provide anti-neoplastic medical expertise that exhibits a synergistic antineoplastic effect on the heat presence and must be imaged to achieve accurate medical assistance. Some articles have shown that the mechanism of molecular involvement in tumormediated erosion of nanoparticles further contributes to the engineering of nanoparticles with suitable properties and composition for synergistic erosion properties [91, 108-111]. For example, in a recent investigation, the biological performance of $\mathrm{ZnO}$ nanoparticles was examined toward the Escherichia Coli bacteria, Candida Albicans, and Pseudomonas aeruginosa. A superior antibacterial activity has vitally occurred about Pseudomonasaeruginosa, which demonstrated that the $\mathrm{ZnO}$ nanoparticles had superb antimicrobial activity against Pseudomonasaeruginosa [112].

\subsection{Drug delivery}

Among the different nanotechnology applications, the delivery of drugs has been proposed as a powerful instrument in the treatment of different diseases, including cancer. The NPs are one of the principal systems in drug delivery. Several investigates have performed $\mathrm{ZnO}-$ NPs for drug delivery applications in the treatment of different diseases. In one study, the loaded $\mathrm{ZnO}$ quantum dots with doxorubicin have been as an influential drug delivery system analyzed by a primary quick drug release followed by a controlled release in vitro. In this survey, $\mathrm{ZnO}$ nanoparticles were encapsulated with chitosan to improve the stability of the nanomaterial led to its cationic charge and hydrophilicity properties [113]. Another major aspect of the application of nanoparticles is their use as a means of gene transfer to various cells, especially tumor cells $[82,114]$. There are several benefits to the application of this system for gene transfer. For instance, the plasmidcontaining expression genes on the surface of NPs can efficiently be targeted and ensure the safety of the gene to recipient tissues [115, 116]. Therefore, nanoparticles can be a good tool for targeting genes to different cells, such as tumor cells. In another survey, Obayemi et al. synthesized quadrupole nanostructures such as $\mathrm{ZnO}$ that could be used as new means of gene carriers [117]. They showed that $\mathrm{ZnO}$ nanostructures, such as silicon-coated amino-modified animals, can bind efficiently to DNA through electrostatic interactions and can improve the transmission yield of melanoma cells [117]. Moreover, Li et al. showed that $\mathrm{ZnO}$ quantum dots with polycationic coatings could transfer DNA to COS-7 cells [118]. Additionally, the use of this system allowed real-time imaging of gene delivery [19, 118, 119]. Different articles have used different oxides of metal nanoparticles as a suitable carrier for gene silencing and gene delivery [120-123]. However, further studies are required in this area.

\subsection{Semiconductors}

$\mathrm{ZnO}$ is remarkably popular as a good semiconductor that has well potential to substitute traditional Cd-related species used in optical and biology fields $[124,125]$. Today, various types of $\mathrm{ZnO}$ nanostructures like nanorings, nanoparticles, nanotubes, and nanorods are well known. Bioimaging use of ZnO-NPs is interesting for scientists [125-128]. For example, bright ZnO-NPs can have well photophysical features [125]. 
It has been indicated that these nanoparticles surfaces can be easily modified. This has been shown that ZnO-NPs can be very stable in aqueous solutions and their quantum yield (QY) can increase up to about $30 \%$ after modification of precision $[129,130]$. $\mathrm{ZnO}$ is generally recognized as a safe substance. $\mathrm{ZnO}$ is used in sunscreen yields and is used in the packaging of food as a food additive. Hence, the luminosity $\mathrm{ZnO}-\mathrm{NP}$ properties can be used in various applications of biological and medical [130].

\subsection{Biosensor}

Biosensors can diagnose various significant biological molecules with high accuracy and sensitivity [114, 131, 132]. Biosensors are mainly used for the detection of various diseases, cell imaging, measurement of nucleotide sequences, etc. Scientists have discovered in recent decades that $\mathrm{ZnO}-\mathrm{NPs}$ can be used in a variety of biological applications. For example, a biosensor based on $\mathrm{ZnO}-\mathrm{NPs}$ was designed for xanthine detection [133]. The first fabricated ZnO-NPs were electro-polymerized in the pyrrole presence on an electrode of platinum to produce a nanocomposite of $\mathrm{ZnO}$ /polypyrrole film which was subsequently stabilized by oxidase of xanthine (XOD) to form the working electrode for the biosensor of xanthine. $\mathrm{The} \mathrm{Ag} / \mathrm{AgCl}$ was performed as the reference electrode and $\mathrm{Pt}$ as an auxiliary electrode to make the sensor. The ZnO-NPs-based biosensors showed a detection restriction of $0.8 \mu \mathrm{M}$. The glucose biosensor was developed by Ren et al. [134] with stabilizing on ZnO-NPs of glucose oxidase. The researchers showed that $\mathrm{ZnO}-\mathrm{NPs}$ containing enzymatic electrodes generated a response current compared to electrodes without nanoparticles, which may be related to the increased catalytic performance of glucose oxidase with the photovoltaic $\mathrm{ZnO}-\mathrm{NP}$ effect $[132,134]$. In another investigation, Zhang et al. [135] designed a semiconductor pyrolytic graphite electrode based on micro peroxidaseimmobilized $\mathrm{ZnO}-\mathrm{NPs}$ that could be used to construct a biosensor to detect hydrogen peroxide by micro peroxidase electrocatalysis. It is suggested that the effect of $\mathrm{ZnO}-\mathrm{NP}$ photovoltaic may increase the activity of catalytic micro peroxidase that can be useful in creating a sensitive sensor to the hydrogen peroxide. The ZnO-NP-based biosensor of cholesterol was developed by Khan et al. [136] as stabilizing cholesterol oxidase on a glass plate of indium-tin-oxide (ITO) containing dispersed CS ZnO-NPs [137]. The scientists showed that a biosensor can be used to detect serum cholesterol. They discovered that ZnO-NPs could significantly be used in the systems of cancer diagnosis. Additionally, Pal and Bhand [138] developed the ZnO-NP-based test of ELISA for detecting serum levels of cancer antigens of embryonic. The detection system consisted of a monoclonal carcinoma embryonic antigen-antibody conjugated to $\mathrm{ZnO}-\mathrm{NP}$, which formed self-assembled monolayers, and even at $1 \mathrm{pg} / \mathrm{ml}$, smaller quantities of antigen were found [139].

\subsection{Catalysts}

Fuel cells use precious metals like platinum (Pt) and their alloys as electrocatalysts. However, catalysts show vulnerability and stability loss to methanol that acts as a barrier to the large-scale use of these environmentally efficient cells. Sandstead et al. [102] produced a composite containing nanostructured doped $\mathrm{ZnO}$ annealed by graphene oxide as a base. They studied its electrocatalytic activity for the reduction of $\mathrm{O}_{2}$ and concluded reactions in which doping nanostructures were stable and conductive. The performance of electrocatalytic was assessed by measuring their CV profile [140-142]. Doped nanostructures showed maximum efficiency for skin bacteria ( $\mathrm{S}$. aureus) and decreasing of the inhibitory area from $37 \%$ to $4 \%$. Therefore, the incorporation of nanostructures of $\mathrm{ZnO}$ into skin creams, UV protection, and nosocomial implants is possible. Sandstead et al. [102] analyzed dyes like alizarine Red.S, thymol blue, methylene red, and methylene blue in a solution of hydrogen peroxide with pure and doped copper $\mathrm{ZnO}$ nanoparticles. Nanostructures with the spherical morphology were given by polyol decrease process by polyvinylpyrrolidone (PVP) as the coating agent. The catalysis was performed under ambient conditions, i.g. in the absence of any light source. Scientists observed that the doping nanostructures increased as the catalyst increased with increasing copper concentration and were very sensitive to Methylene Blue (MB). Hence, $\mathrm{ZnO}$ nanostructures have been feasible and efficient for colorless photo-degradation [143145].

\subsection{Photoelectron devices}

The characterization of one-dimensional (1D) nanowires - like strong light-emitting, light absorption, and optical conductivity - can improve the light-emitting diodes (LEDs) performance, optical detectors, sensors, solar cells, field-effect transistors, and nanogenerators. For instance, nanowires of $\mathrm{ZnO}$ act as carrier conduction channels in photoelectric devices and reduce the carrier loss of light produced [145-147]. The LEDs' performance and nanowire-based detectors of photoelectric could be improved compared to tools based on thin films of polycrystalline [148, 149]. This paper investigates the sol-gel method for the synthesis of $1 \mathrm{D} \mathrm{ZnO}$ nanostructures and the growth effect parameters on morphology and growth rate. The main uses of 1D $\mathrm{ZnO}$ nanostructures in optoelectronic devices are discussed. Many methods for improving the performance of $1 \mathrm{D} \mathrm{ZnO}$-based devices are discussed including inactivation of surface, the effect of photonic and localized surface plasmons. A schematic design of the LED homojunction is provided in Fig. 8a. In the forward bias, UV emission was predominant from the free recombination of exciton with a concentration of about $380 \mathrm{~nm}$, and a weak broad peak of about 630 $\mathrm{nm}$ was viewed in the EL collected of the spectrum at ambient temperature [150]. A plan image of the LED is shown in Fig. 8b. The EL spectrum in Fig. $8 \mathrm{~b}$ shows that the LED presents the excited EL emission at about $380 \mathrm{~nm}$ in the forward bias [151-154].

\subsection{Textile}

Different antimicrobial agents have been utilized in the textile industry and most of them are biocides. Using inorganic nanoparticles has developed immediately owing to many investigations done in the modification and formation of particles for biomedical applications. Various heavy metals and metal oxides either pure or in composites at very low concentrations are toxic to microbes. They can remove bacteria by different processes, including direct damage to cell walls, generation of reactive oxygen species, and via binding to intracellular proteins and inactivating them. Silver $(\mathrm{Ag}), \mathrm{ZnO}$, copper oxide $(\mathrm{CuO})$, magnesium oxide $(\mathrm{MgO})$, and titanium dioxide $\left(\mathrm{TiO}_{2}\right)$ are several common inorganic materials used in the synthesis of antimicrobial coatings [155]. For example, loaded $\mathrm{ZnO}$ nanoparticles on textiles based on cotton fabrics were dried and washed before use. The modification methods were done on samples with a maximum size of 15 to $30 \mathrm{~cm}$. Cotton clothes were coated with a solution of ZnO-NPs at 


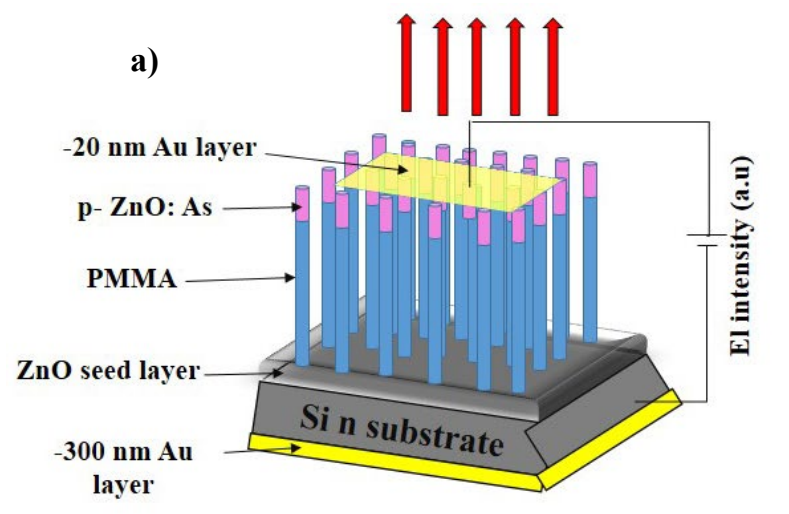

b)

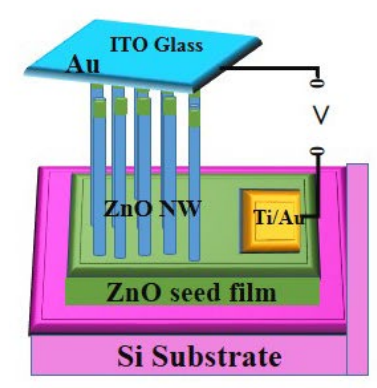

Fig. 8. Schematic design of a) a doped nanorod of $\mathrm{p}-\mathrm{ZnO} / \mathrm{n}-\mathrm{ZnO}$ LED of homojunction and b) the nanowire of Au/ZnO LED of Schottky.

certain concentrations indicated by MIC (minimum inhibitory concentration) and in vitro cytotoxicity. For sequential fabrics treatment with colloidal $\mathrm{ZnO}$, the solution was stirred continuously. All samples were immersed in a colloidal bath for 5 minutes and then pressed with a laboratory pad at constant pressure up to $100 \%$ wet. The samples were dried at $80^{\circ} \mathrm{C}$ for 5 minutes and then dried at $150{ }^{\circ} \mathrm{C}$ for 2 minutes. The following treatments were performed: (1) control that without soybean trypticase (TSB) broth inoculation with bacterial culture (negative control), untreated fabrics in TSB inoculated with bacterial culture (positive control), untreated fabrics in TSB appeared without inoculation (blank) (2) fabrics treated with ZnO-NPs solution [156-158]. Fabric dyes treated with silver or zinc oxide nanoparticles are used to functionalize textile materials. The final product with antibacterial capabilities is determined by embedding these nanoparticles in the structure of other materials. Indigo and commercial dyes have participated in the investigation. It is worth noting that nanoparticles of silver were given in response to the process preparation and indigo dye used for preparing dye commercial baths on site. This approach makes it possible to reduce technological steps. The modified dyes were used to dye cotton fibers. The antimicrobial properties of the textile of the final material were investigated [159, 160].

\section{Conclusions}

$\mathrm{ZnO}$ nanoparticles because of their short size compared to the same materials with bulk shape, have obtained different properties and therefore new advances in biomedicine, biosensors, and biotechnology. They are synthesized by various methods to make affordable metal nanoparticles that are easily scalable and environmentally safe. This is especially true for the production of nanoparticles which should be free of toxic contaminants in applications of therapeutic. The synthesis techniques can provide nanoparticles that have morphology and controlled size. Among these methods, the method of sol-gel is the well-established synthesis method for the preparation of high-quality ZnO-NPs and also composites of mixed oxides. The properties of solgel $\mathrm{ZnO}-\mathrm{NPs}$, due to the controlled stabilization patterning nanostructures, modulation of shape, and low temperature for processing have been suitable for numerous applications in many fields. In medicine, nanoparticles are performed as agents of antimicrobial-like bandages. Applications are being developed for targeted drug delivery and clinical diagnosis. Sol-gel ZnO-NPs are one of the nanomaterials that have many biomedical applications and could be safely generated at a low cost. However, synthesis methods of these promising particles are expected to be advanced with more desirable features in the future.

\section{References}

[1] A.G.Mamalis, Recent advances in nanotechnology, J. Mater. Process. Technol. 181 (2007) 52-58. https://doi.org/10.1016/j.jmatprotec.2006.03.052.

[2] L. Shao, J. Chen, Synthesis and application of nanoparticles by a high gravity method, China Particuology. 3 (2005) 134-135. https://doi.org/10.1016/S1672-2515(07)60180-8.

[3] A. Khaleel, P.N. Kapoor, K.J. Klabunde, Nanocrystalline metal oxides as new adsorbents for air purification, Nanostructured Materials. 11 (1999) 459-468. https://doi.org/10.1016/S09659773(99)00329-3.

[4] M. Lin, Y. Zhao, S. Wang, M. Liu, et al., Recent advances in synthesis and surface modification of lanthanide-doped upconversion nanoparticles for biomedical applications, Biotechnol. Adv. 30 (2012) 1551-1561. https://doi.org/10.1016/j.biotechadv.2012.04.009.

[5] R. Baron, F.W. Campbell, I. Streeter, et al., Facile method for the construction of random nanoparticle arrays on a carbon support for the development of well-defined catalytic surfaces, Int. J. Electrochem. Sci. 3 (2008) 556-565.

[6] K. Nakahara, H. Takasu, Interactions between gallium and nitrogen dopants in $\mathrm{ZnO}$ films grown by radical-source molecular-beam epitaxy, Appl. Phys. Lett. 79 (2001) 4139-4141. https://doi.org/10.1063/1.1424066.

[7] J. Jeevanandam, A. Barhoum, Y.S. Chan, A. Dufresne, M.K. Danquah, Review on nanoparticles and nanostructured materials: history, sources, toxicity and regulations, Beilstein J. Nanotechnol. 9 (2018) 1050-1074. https://doi.org/10.3762/bjnano.9.98.

[8] F. Sharifianjazi, A.H. Pakseresht, M. Shahedi Asl, A. Esmaeilkhanian, et al., Hydroxyapatite consolidated by zirconia: applications for dental implant, J. Compos. Compd. https://doi.org/10.29252/jcc.2.1.4.

[9] Z.L. Wang Lin, Oxide nanobelts and nanowires - growth, properties and applications, J. Nanosci. Nanotechnol. https://doi.org/10.1166/jnn.2008.N08.

[10] M.H. Habibi, R. Sheibani, Nanostructure silver-doped zinc oxide films coating on glass prepared by sol-gel and photochemical deposition process: Application for removal of mercaptan, J. Ind. Eng. Chem. 19 (2013) 161-165. https://doi.org/10.1016/j.jiec.2012.07.019. 
[11] M. Khanpour, A. Morsali, Synthesis and characterization of onedimensional zinc (II) coordination polymers as precursors for preparation of $\mathrm{ZnO}$ nanoparticles via thermal decomposition, J. Inorg. Organomet. Polym. Mater. 21 (2011) 360-364. https://doi.org/10.1007/s10904-010-9450-x.

[12] M.H. Habibi, E. Askari, Thermal and structural studies of zinc zirconate nanoscale composite derived from sol-gel process, J. Therm. Anal. Calorim. 111 (2013) 227-233. https://doi.org/10.1007/s10973-012-2205-x.

[13] Z.M. Khoshhesab, M. Sarfaraz, Z. Houshyar, Influences of urea on preparation of zinc oxide nanostructures through chemical precipitation in ammonium hydrogencarbonate solution, Synth. React. Inorg. Metal-Organic Nano-Metal Chemi. 42 (2012) 13631368. https://doi.org/10.1080/15533174.2012.680119.

[14] M. Edrissi, M. Soleymani, S. Akbari, Parameters Optimization Based on the Taguchi Robust Design for the Synthesis of CuO-ZnO Nanocomposite Using the Surfactant-Assisted Coprecipitation Method, Synth. React. Inorg. Metal-Organic Nano-Metal Chemi. 41 (2011) 1282-1287. https://doi.org/10.1080/15533174.2011.594841.

[15] Z.M. Khoshhesab, M. Sarfaraz, M.A. Asadabad, Preparation of ZnO nanostructures by chemical precipitation method, Synth. React. Inorg. Metal-Organic Nano-Metal Chemi.41 (2011) 814-819. https://doi.org/10.1080/15533174.2011.591308.

[16] I. Khan, K. Saeed, I. Khan, Nanoparticles: Properties, applications and toxicities, Arab. J. Chem. 12 (2019) 908-931. https://doi.org/10.1016/j.arabjc.2017.05.011.

[17] E. Asadi, A. Fassadi Chimeh, S. Hosseini, S. Rahimi, et al. A review of clinical applications of graphene quantum dot-based composites. J. compos. compd. 1 (2019) 31-40. https://jourcc.com/index.php/jourcc/article/view/jcc116.

[18] V.K.H. Bui, M.K. Kumar, M. Alinaghibeigi, S. Moolayadukkam, et al., A review on zinc oxide composites for energy storage applications: solar cells, batteries, and supercapacitors, J. compos. compd. 3 (2021) 182-193. https://doi.org/10.52547/jec.3.3.6.

[19] F. Niazvand, A. Cheshmi, M. Zand, R. NasrAzadani, et al., An overview of the development of composites containing $\mathrm{Mg}$ and $\mathrm{Zn}$ for drug delivery, J. compos. compd. 2 (2020) 193-204. https://doi.org/10.29252/jcc.2.4.4.

[20] A.K. Zak, W.H.abd. Majid, H.Z. Wang, R. Yousefi, et al., Sonochemical synthesis of hierarchical $\mathrm{ZnO}$ nanostructures, Ultrason. sonochem. 20 (2013) 395-400. https://doi.org/10.1016/j.ultsonch.2012.07.001.

[21] R. Zamiri, A. Zakaria, H. Abbastabar Ahangar, M. Darroudi, et al., Aqueous starch as a stabilizer in zinc oxide nanoparticle synthesis via laser ablation, J. Alloys Compd. 516 (2012) 41-48. https://doi.org/10.1016/j.jallcom.2011.11.118.

[22] C.-L. Kuo, C.-L. Wang, H.-H. Ko, W.-S. Hwang, et al., Synthesis of zinc oxide nanocrystalline powders for cosmetic applications, Ceram. Int. 36 (2010) 693-698. https://doi.org/10.1016/j.ceramint.2009.10.011.

[23] C. Deng, H. Hu, G. Shao, C. Han, Facile template-free sonochemical fabrication of hollow $\mathrm{ZnO}$ spherical structures, Mater. Lett. 64 (2010) 852-85. https://doi.org/10.1016/j.matlet.2010.01.039.

[24] P. Jajarmi, Fabrication of pure $\mathrm{ZnO}$ nanoparticles by polymerization method, Mater. Lett. 63 (2009) 2646-2648. https://doi.org/10.1016/j.matlet.2009.08.062.

[25] R. Song, Y. Liu, L. He, Synthesis and characterization of mercaptoacetic acid-modified $\mathrm{ZnO}$ nanoparticles, Solid State Sci. 10 (2008) 1563-1567. https://doi.org/10.1016/j.solidstatesciences.2008.02.006.

[26] H. Xu, H. Wang, Y. Zhang, W. He, et al., Hydrothermal synthesis of zinc oxide powders with controllable morphology, Ceram. Int. 30 (2004) 93-97. https://doi.org/10.1016/S0272-8842(03)00069-5.

[27] O. Singh, N. Kohli, R.C. Singh, Precursor controlled morphology of zinc oxide and its sensing behaviour, Sens. Actuators B Chem. 178 (2013) 149-154. https://doi.org/10.1016/j.snb.2012.12.053.
[28] S. Nasibi, K. Alimohammadi, L. Bazli, S. Eskandarinezhad, et al., TZNT alloy for surgical implant applications: A systematic review, J. Compos. Compd. 2 (2020) 62-68. https://doi.org/10.29252/jcc.2.2.1.

[29] F.A. Alharthi, N. Al-Zaqri, A. El marghany, A.A. Alghamdi, et al., Synthesis of nanocauliflower $\mathrm{ZnO}$ photocatalyst by potato waste and its photocatalytic efficiency against dye, J. Mater. Sci. Mater. 31 (2020) 11538-11547. https://doi.org/10.1007/s10854-020-03701-3.

[30] H.N. khoramabadi, M. Arefian, M. Hojjati, I. Tajzad, et al., A review of Polyvinyl alcohol/Carboxymethyl cellulose (PVA/CMC) composites for various applications, J. Compos. Compd. 2 (2020) 69-76. https://doi.org/10.29252/jcc222.

[31] A. Kazemzadeh, M.A. Meshkat, H. Kazemzadeh, M. Moradi, et al., Preparation of graphene nanolayers through surfactant-assisted pure shear milling method, J. Compos. Compd. 1 (2019) 22-26. https://doi.org/10.29252/jcc.1.1.4.

[32] E.I. Naik, H.S. Bhojya Naik, R. Viswanath, et al., Effect of zirconium doping on the structural, optical, electrochemical and antibacterial properties of $\mathrm{ZnO}$ nanoparticles prepared by sol-gel method, Chem. Data Collect.29 (2020) 100505. https://doi.org/10.1016/j.cdc.2020.100505.

[33] S. Mourad, J. El Ghoul, K. Khirouni, Role of indium doping on structural and electrical properties of $\mathrm{ZnO}$ nanoparticles prepared by sol-gel method, J. Mater. Sci. Mater., 31 (2020) 6372-6384. https://doi.org/10.1007/s10854-020-03193-1.

[34] P. Simon, Y. Gogotsi, Materials for electrochemical capacitors, J. Nanosci. Nanotechnol. (2009) 320-329. https://doi.org/10.1142/9789814287005_0033.

[35] A. Kumar, Sol gel synthesis of zinc oxide nanoparticles and their application as nano-composite electrode material for supercapacitor, J. Mol. Struct. 1220 (2020) 128654. https://doi.org/10.1016/j.molstruc.2020.128654.

[36] H.W. Jang, A. Zareidoost, M. Moradi, A. Abuchenari, et al., Photosensitive nanocomposites: environmental and biological applications, J. Compos. Compd. 2 (2020) 50-60. https://doi.org/10.29252/jcc.2.1.7.

[37] S. Saadi, Nazari, Recent developments and applications of nanocomposites in solar cells: a review, J. Compos. Compd. 1 (2019) 41-50. https://doi.org/10.29252/jcc.1.1.7.

[38] A. Kumar, N. Yadav, M. Bhatt, N. Mishra, et al., Sol-gel derived nanomaterials and it's applications: a review, Res.J.chem.sci. 5 (2015) 98-105.

[39] T.M. Mahato, G.K. Prasad, B. Singh, J. Acharya, et al., Nanocrystalline zinc oxide for the decontamination of sarin, J. Hazard. Mater. 165 (2009) 928-932. https://doi.org/10.1016/j.jhazmat.2008.10.126.

[40] M. Ristić, S. Musić, M. Ivanda, S. Popović, Sol-gel synthesis and characterization of nanocrystalline $\mathrm{ZnO}$ powders, J. Alloys Compd. 397 (2005) L1-L4. https://doi.org/10.1016/j.jallcom.2005.01.045.

[41] B.B. Lakshmi, P.K. Dorhout, C.R. Martin, Sol- gel template synthesis of semiconductor nanostructures, Chem. Mater. 9 (1997) 857-862. https://doi.org/10.1021/cm9605577.

[42]J. Daraei, Production and characterization of PCL (Polycaprolactone) coated TCP/nanoBG composite scaffolds by sponge foam method for orthopedic applications. J. Compos. Compd. 2 (2020) 44-49. https://doi.org/10.29252/jcc.2.1.6.

[43] S. Yue, Z. Yan, Y. Shi, G. Ran, Synthesis of zinc oxide nanotubes within ultrathin anodic aluminum oxide membrane by sol-gel method, Mater. Lett. 98 (2013) 246-249. https://doi.org/10.1016/j.matlet.2013.02.037.

[44] J. Mayekar, V. Dahr, and S. Radha, To study the role of temperature and sodium hydroxide concentration in the synthesis of zinc oxide nanoparticles, Int. J. Sci. Res. Pub. 3 (2013) 2250-3153.

[45] S. Zavar, A novel three component synthesis of 2-amino-4Hchromenes derivatives using nano $\mathrm{ZnO}$ catalyst. Arab. J. Chem. 10 (2017) S67-S70. https://doi.org/10.1016/j.arabjc.2012.07.011.

[46] A. Abuchenari, M. Moradi, The Effect of Cu-substitution on the microstructure and magnetic properties of $\mathrm{Fe}-15 \% \mathrm{Ni}$ alloy prepared 
by mechanical alloying, J. Compos. Compd. 1 (2019) 10-15. https://doi.org/10.29252/jcc.1.1.2.

[47] S. Sabir, M. Arshad, S.K. Chaudhari, Zinc oxide nanoparticles for revolutionizing agriculture: synthesis and applications, Sci. World J. (2014) 925494. https://doi.org/10.1155/2014/925494.

[48] Z. Goudarzi, A. Ijadi, A. Bakhtiari, S. Eskandarinezhad, et al., Srdoped bioactive glasses for biological applications, J. Comp. Compd. 2 (2020) 105-109. https://doi.org/10.29252/jcc.2.2.7.

[49] X.Y. Kong, Z.L. Wang, Spontaneous polarization-induced nanohelixes, nanosprings, and nanorings of piezoelectric nanobelts, Nano Letters. 3 (2003) 1625-1631. https://doi.org/10.1021/n1034463p.

[50] D. Gnanasangeetha, D.S. Thambavani, Biogenic production of zinc oxide nanoparticles using Acalypha indica, J. Chem. Biolog. Physic. Sci. 4 (2013) 238-246.

[51] L. Bazli, H. Nargesi khoramabadi, A. Modarresi Chahardehi, H. Arsad, et al., Factors influencing the failure of dental implants: A Systematic Review, J. Comp. Compd. 2 (2020) 18-25. https://doi.org/10.29252/jcc.2.1.3.

[52] C.Y. Lee, Effect of phosphorus dopant on photoluminescence and field-emission characteristics of Mg 0.1 Zn 0.9 O nanowires, J. Appl. Physic. 99 (2006) 024303. https://doi.org/10.1063/1.2161420.

[53] C. Chen, J. Liu, P. Liu, B. Lu, Investigation of photocatalytic degradation of Methyl Orange by Using nano-sized $\mathrm{ZnO}$ catalysts, Chem. Eng. J. 144 (2008) 509-513. DOI:10.4236/aces.2011.11002.

[54] K. Zhang, Q. Van Le, Bioactive glass coated zirconia for dental implants: a review, J. Comp. Compd. 2 (2020) 10-17. https://doi.org/10.29252/jcc.2.1.2.

[55] M. Ferdosi Heragh, S. Eskandarinezhad, A. Dehghan, Ni-Cu matrix composite reinforced with CNTs: preparation, characterization, wear and corrosion behavior, inhibitory effects, J. Comp. Compd. 2 (2020) 123-128. https://doi.org/10.29252/jcc.2.3.3.

[56] M. Hudlikar, S. Joglekar, M. Dhaygude, K. Kodam, Latex-mediated synthesis of $\mathrm{ZnS}$ nanoparticles: green synthesis approach, J. Nanopart. Res. 14 (2012) 1-6. https://doi.org/10.1007/s11051-0120865-x.

[57] G. Singhal, R. Bhavesh, K. Kasariya, A. Ranjan Sharma, R. Pal Singh, Biosynthesis of silver nanoparticles using Ocimum sanctum (Tulsi) leaf extract and screening its antimicrobial activity. J. Nanopart. Res. 13 (2011) 2981-2988. https://doi.org/10.1007/s11051-010-0193-y.

[58] A.H. Shahbaz, M. Esmaeilian, R. NasrAzadani, K. Gavanji, The effect of $\mathrm{MgF} 2$ addition on the mechanical properties of hydroxyapatite synthesized via powder metallurgy, J. Comp. Compd. 1 (2019) 16-21. https://doi.org/10.29252/jcc.1.1.3.

[59] L. Bazli, M. Yusuf, A. Farahani, Application of composite conducting polymers for improving the corrosion behavior of various substrates: A Review, J. Comp. Compd. 2 (2020) 228-240. https://doi.org/10.29252/jcc.2.4.7.

[60] A.Jafari Rad, Synthesis of copper oxide nanoparticles on activated carbon for pollutant removal in Tartrazine structure, J Comp. Compd. 2 (2020) 99-104. https://doi.org/10.29252/jcc.2.2.6.

[61] K. Sun, M.T. McDowell, A.C. Nielander, S. Hu, et al., J. Phys. Chem. Lett. 6 (2015) 592-598. https://doi.org/10.1021/jz5026195.

[62] A.G. Scheuermann, J. P. Lawrence, K. W. Kemp, T. Ito, et al., Design principles for maximizing photovoltage in metal-oxideprotected water-splitting photoanodes, Nature mater. 15 (2016) 99105. https://doi.org/10.1038/nmat4451.

[63] H. Qi, J. Wolfe, D. Fichou, Z. Chen, Cu2O photocathode for low bias photoelectrochemical water splitting enabled by NiFe-layered double hydroxide co-catalyst, Sci. Rep. 6 (2016) 1-8. https://doi.org/10.1038/srep30882.

[64] L. Bazli, M. Siavashi, A. Shiravi, A review of carbon nanotube/TiO2 composite prepared via sol-gel method, J. Comp. Compd. 1 (2019) 1-9. https://doi.org/10.29252/jcc.1.1.1.

[65] Z. Irshad, M. Adnan, J.K. Lee, Controlling phase and morphology of all-dip-coating processed $\mathrm{HC}(\mathrm{NH} 2) 2 \mathrm{PbI} 3$ perovskite layers from an aqueous halide-free lead precursor, J. Phys. Chem. Solids. 160 (2022) 110374. https://doi.org/10.1016/j.jpcs.2021.110374.

[66] I. Tajzad, E. Ghasali, Production methods of CNT-reinforced Al matrix composites: a review, J. Comp. Compd. 2 (2020) 1-9. https://doi.org/10.29252/jcc.2.1.1.

[67] S. Gupta, M. Tripathi, A review on the synthesis of TiO2 nanoparticles by solution route, Open Chem. J. 10 (2012) 279-294. https://doi.org/10.2478/s11532-011-0155-y.

[68] A. Abuchenari, K. Hardani, S. Abazari, F. Naghdi, et al., Clayreinforced nanocomposites for the slow release of chemical fertilizers and water retention, J. Comp. Compd. 2 (2020) 85-91. https://doi.org/10.29252/jcc.2.2.4.

[69] N. Hassan, M.R. Hashim, M. Bououdina, One-dimensional ZnO nanostructure growth prepared by thermal evaporation on different substrates: ultraviolet emission as a function of size and dimensionality, Ceram. Int. 39 (2013) 7439-7444. https://doi.org/10.1016/j.ceramint.2013.02.088.

[70] R. Ullah, J. Dutta, Photocatalytic degradation of organic dyes with manganese-doped ZnO nanoparticles, J. Hazard. Mater. 156 (2008) 194-200. https://doi.org/10.1016/j.jhazmat.2007.12.033.

[71] M. Hossain, C.Y.H. Lim, Growth of zinc oxide nanowires and nanobelts for gas sensing applications, J. nanocryst. mater. 23 (2005) 27-30. https://doi.org/10.4028/www.scientific.net/JMNM.23.27.

[72] H.M. Yadav, J.-S. Kim, and S.H. Pawar, Developments in photocatalytic antibacterial activity of nano TiO2: A review, Korean. J. Chem. Eng. 33 (2016) 1989-1998. https://doi.org/10.1007/s11814-016-0118-2.

[73] C. Hariharan, Photocatalytic degradation of organic contaminants in water by $\mathrm{ZnO}$ nanoparticles: Revisited, Appl. Catal. A: Gen. 304 (2006) 55-61. https://doi.org/10.1016/j.apcata.2006.02.020.

[74] D. Ju, H. Xu, J. Zhang, J. Guo, B. Cao, Direct hydrothermal growth of $\mathrm{ZnO}$ nanosheets on electrode for ethanol sensing, Sens. Actuators B Chem. 201(2014) 444-451.

https://doi.org/10.1016/j.snb.2014.04.072.

[75] S. Yue, J. Lu, J. Zhang, Synthesis of three-dimensional ZnO superstructures by a one-pot solution process, Mater. Chem. Physic. 117 (2009) 4-8. https://doi.org/10.1016/j.matchemphys.2009.05.010.

[76] R. Adnan, N.A. Razana, I. Abdul Rahman, M. Akhyar Farrukh, Synthesis and Characterization of High Surface Area Tin Oxide Nanoparticles via the Sol-Gel Method as a Catalyst for the Hydrogenation of Styrene, J Chin Chem Soc. 57 (2010) 222-229. https://doi.org/10.1002/jccs.201000034.

[77] A. Sagasti, N. Bouropoulos, D. Kouzoudis, A. Panagiotopoulos, et al., Nanostructured $\mathrm{ZnO}$ in a metglas/ZnO/hemoglobin modified electrode to detect the oxidation of the hemoglobin simultaneously by cyclic voltammetry and magnetoelastic resonance, Mater. 10 (2017) 849. https://doi.org/10.3390/ma10080849.

[78] T. Nagase, T. Ooie, J. Sakakibara, A novel approach to prepare zinc oxide films: excimer laser irradiation of sol-gel derived precursor films, Thin Solid Films. 357 (1999) 151-158. https://doi.org/10.1016/S0040-6090(99)00645-8.

[79] Y. Zhang, E. Xie, Nature of room-temperature ferromagnetism from undoped ZnO nanoparticles, Appl. Physic. A. 99 (2010) 955-960. https://doi.org/10.1007/s00339-010-5703-3.

[80] J. Chen, J. Wang, R.F. Zhuo, D. Yan, et al., The effect of Al doping on the morphology and optical property of $\mathrm{ZnO}$ nanostructures prepared by hydrothermal process, Appl. Surf. Sci. 255 (2009) 39593964. https://doi.org/10.1016/j.apsusc.2008.10.086.

[81] K. Gold, B. Slay, M. Knackstedt, A.K. Gaharwar, Antimicrobial activity of metal and metal-oxide based nanoparticles, Adv. Ther. 1 (2018) 1700033. https://doi.org/10.1002/adtp.201700033.

[82] Z. Sadowski, A. Pawlowska, Synthesis of metal oxide nanoparticles and its biomedical applications, Pharm. Technol. (2017) 91-111. https://doi.org/10.1007/978-3-319-70299-5_4.

[83] G. Sangeetha, S. Rajeshwari, and R. Venckatesh, Green synthesis of zinc oxide nanoparticles by aloe barbadensis miller leaf extract: 
Structure and optical properties, Mater. Res. Bull.46 (2011) 25602566. https://doi.org/10.1016/j.materresbull.2011.07.046.

[84] M. Darroudi, Z. Sabouri, R. Kazemi Oskuee, A. Khorsand Zak, Solgel synthesis, characterization, and neurotoxicity effect of zinc oxide nanoparticles using gum tragacanth, Ceram. Int. 39 (2013) 91959199. https://doi.org/10.1016/j.ceramint.2013.05.021.

[85]O.V. Salata, Applications of nanoparticles in biology and medicine, J. Nanobiotechnol. 2 (2004) 1-6. https://doi.org/10.1186/1477-3155-23.

[86] M.D. Newman, M. Stotland, J.I. Ellis, The safety of nanosized particles in titanium dioxide-and zinc oxide-based sunscreens, JAAD. 61 (2009) 685-692. https://doi.org/10.1016/j.jaad.2009.02.051.

[87] Z. Huang, X. Zheng, D. Yan, G. Yin, et al., Toxicological effect of $\mathrm{ZnO}$ nanoparticles based on bacteria, Langmuir. 24 (2008) 41404144. https://doi.org/10.1021/la7035949.

[88] L.K. Limbach, P. Wick, P. Manser, R.N. Grass, et al., Exposure of engineered nanoparticles to human lung epithelial cells: influence of chemical composition and catalytic activity on oxidative stress, Environ. Sci. Technol.41 (2007) 4158-4163. https://doi.org/10.1021/es062629t.

[89] M. Husseiny, M. Abd El-Aziz, Y. Badr, M.A. Mahmoud, Biosynthesis of gold nanoparticles using Pseudomonas aeruginosa, Spectrochim. Acta A Mol. Biomol. Spectrosc. 67 (2007) 1003-1006. https://doi.org/10.1016/j.saa.2006.09.028.

[90] M. Premanathan, K. Karthikeyan, K. Jeyasubramanian, G. Manivannan, Selective toxicity of $\mathrm{ZnO}$ nanoparticles toward Grampositive bacteria and cancer cells by apoptosis through lipid peroxidation, Nanotechnol. Biol. Med. 7 (2011) 184-192. https://doi.org/10.1016/j.nano.2010.10.001.

[91] H. Zhang, Y. Shan, L. Dong, A comparison of TiO2 and ZnO nanoparticles as photosensitizers in photodynamic therapy for cancer. J. Biomed. Nanotech. 10 (2014) 1450-1457. https://doi.org/10.1166/jbn.2014.1961.

[92] F. Aldeek, C. Mustin, L. Balan, G. Medjahdi, Enhanced photostability from CdSe (S)/ZnO core/shell quantum dots and their use in biolabeling, EurJIC. 2011 (2011) 794-801. https://doi.org/10.1002/ejic.201000790.

[93] H. Mirzaei, M. Darroudi, Zinc oxide nanoparticles: Biological synthesis and biomedical applications, Ceram. Int. 43 (2017) 907914. https://doi.org/10.1016/j.ceramint.2016.10.051.

[94] A. Khorsand Zak, R. Razali, W.H.B. Abd Majid, M. Darroudi, Synthesis and characterization of a narrow size distribution of zinc oxide nanoparticles, Int. J. Nanomedicine. 6 (2011) 1399-1403. https://doi.org/10.2147/IJN.S19693.

[95] A.K. Barui, R. Kotcherlakota, C.R. Patra, Biomedical applications of zinc oxide nanoparticles, in Inorganic frameworks as smart nanomedicines, Elsevier. (2018) 239-278. https://doi.org/10.1016/B978-0-12-813661-4.00006-7.

[96] S. Rajeshkumar, D. Sandhiya, Biomedical applications of zinc oxide nanoparticles synthesized using eco-friendly method, Nanoparticles and their Biomedical Applications. (2020) 65-93. https://doi.org/10.1007/978-981-15-0391-7_3.

[97] H. Khalilpour, P. Shafiee, A. Darbandi, M. Yusuf, et al., Application of Polyoxometalate-based composites for sensor systems: A review, J. Comp. Compd. 3 (2021) 129-139. https://doi.org/10.52547/jcc.3.2.6.

[98] J.W. Rasmussen, E. Martinez, P. Louka, D. G Wingett, Zinc oxide nanoparticles for selective destruction of tumor cells and potential for drug delivery applications, Expert Opin. Drug Deliv. 7 (2010) 1063-1077. https://doi.org/10.1517/17425247.2010.502560.

[99] K.M. Hambidge, C. Hambidge, M. Jacobs, J.D. Baum, Low levels of zinc in hair, anorexia, poor growth, and hypogeusia in children, Pediatr. Res. 6 (1972) 868-874. https://doi.org/10.1203/00006450197212000-00003.
[100] N. Roohani, R. Hurrell, R. Kelishadi, R. Schulin, Zinc and its importance for human health: An integrative review, J. Res. Med. Sci. 18 (2013) 144-57.

[101] R. Roy, S. Kumar, A.K. Verma, A. Sharma, et al., Zinc oxide nanoparticles provide an adjuvant effect to ovalbumin via a Th2 response in Balb/c mice, Int. Immunol. 26 (2014) 159-172. https://doi.org/10.1093/intimm/dxt053.

[102] H.H. Sandstead, Understanding zinc: recent observations and interpretations, J. Lab. Clin. Med. 124 (1994) 322-327.

[103] J.T. Seil, T.J. Webster, Antibacterial effect of zinc oxide nanoparticles combined with ultrasound, Nanotechnol. 23 (2012) 495101. https://doi.org/10.1088/0957-4484/23/49/495101.

[104] X. Zhu, I. Yuri, X. Gan, I. Suzuki, G. Li, Electrochemical study of the effect of nano-zinc oxide on microperoxidase and its application to more sensitive hydrogen peroxide biosensor preparation, Biosens. Bioelectron. 22 (2007) 1600-1604. https://doi.org/10.1016/j.bios.2006.07.007.

[105] P. Shafiee, S.A. Alavi, M. Rezaei, F. Jokar, Promoted Ni-Co$\mathrm{A} 12 \mathrm{O} 3$ nanostructured catalysts for $\mathrm{CO} 2$ methanation, Int. J. Hydrog. Energy. (2021). https://doi.org/10.1016/j.ijhydene.2021.10.197.

[106] N. Jain, A. Bhargava, J. C. Tarafdar, S. K. Singh, J. Panwar, A biomimetic approach towards synthesis of zinc oxide nanoparticles, Appl. Microbiol. Biotechnol. 97 (2013) 859-869.

https://doi.org/10.1007/s00253-012-3934-2.

[107] C. Jayaseelan, A. Abdul Rahuman, A. Vishnu Kirthi, S. Marimuthu, et al., Novel microbial route to synthesize $\mathrm{ZnO}$ nanoparticles using Aeromonas hydrophila and their activity against pathogenic bacteria and fung, Spectrochim. Acta A Mol. Biomol. Spectrosc. 90 (2012) 78-84. https://doi.org/10.1016/j.saa.2012.01.006.

[108] C.H. Ramamurthy, K.S. Sampath, P. Arunkumar, M. Suresh Kumar, et al., Green synthesis and characterization of selenium nanoparticles and its augmented cytotoxicity with doxorubicin on cancer cells, Bioprocess. Biosyst. Eng. 36 (2013) 1131-1139. https://doi.org/10.1007/s00449-012-0867-1.

[109] X. Wang, H. Chen, Y. Zheng, et al., Au-nanoparticle coated mesoporous silica nanocapsule-based multifunctional platform for ultrasound mediated imaging, cytoclasis and tumor ablation, Biomater. 34 (2013) 2057-2068. https://doi.org/10.1016/j.biomaterials.2012.11.044.

[110] M.J. Akhtar, M. Ahamed, S. Kumar, M. Majeed Khan, et al., Zinc oxide nanoparticles selectively induce apoptosis in human cancer cells through reactive oxygen species, Int. J. Nanomedicine.7 (2012) 845-857. https://doi.org/10.2147/IJN.S29129.

[111] B.E. Urban, P.B Neogi, S.J. Butler, et al., Second harmonic imaging of plants tissues and cell implosion using two-photon process in $\mathrm{ZnO}$ nanoparticles, J. Biophotonics. 5 (2012) 283-291. https://doi.org/10.1002/jbio.201100076.

[112] Y. Kumar, V. Singh, A. Pandey, et al., AIP Conf. Proc. 030119 (2020). https://doi.org/10.1063/5.0017120.

[113] Q. Yuan, S. Hein, R.D.K. Misra, New generation of chitosanencapsulated $\mathrm{ZnO}$ quantum dots loaded with drug: Synthesis, characterization and in vitro drug delivery response, Acta Biomater. 6 (2010) 2732-2739. https://doi.org/10.1016/j.actbio.2010.01.025.

[114] F.S. Rezaei, F. Sharifianjazi, A. Esmaeilkhanian, E. Salehi, Chitosan films and scaffolds for regenerative medicine applications: A review, Carbohydr. Polym. 273 (2021) 118631. https://doi.org/10.1016/j.carbpol.2021.118631.

[115] C.S.S.R. Kumar, F. Mohammad, Magnetic nanomaterials for hyperthermia-based therapy and controlled drug delivery, Adv. Drug Deliv. Rev. 63 (2011) 789-808. https://doi.org/10.1016/j.addr.2011.03.008.

[116] J. Li, S. Wu, C. Wu, L. Qiu, et al., Versatile surface engineering of porous nanomaterials with bioinspired polyphenol coatings for targeted and controlled drug delivery, Nanoscale. 8 (2016) 86008606. https://doi.org/10.1039/C6NR00600K. 
[117] J.D. Obayemi, K.A. Malatesta, O.s. Odusanya, D. Yiporo, et al., Abstract C60: injectable, biodegradable micro-and nano-particles loaded with prodigiosin-based drug for localized anticancer drug delivery, CEBP. 25 (2016). DOI: 10.1158/1538-7755.DISP15-C60.

[118] Q. Li, Y. Wen, J. Wen, et al., A new biosafe reactive oxygen species (ROS)-responsive nanoplatform for drug delivery, RSC Adv. 6 (2016) 38984-38989. https://doi.org/10.1039/C5RA25913D.

[119] A. Bakhtiari, A. Cheshmi, M. Naeimi, S. Mohammadi Fathabad, et al., Synthesis and characterization of the novel $80 \mathrm{~S}$ bioactive glass: bioactivity, biocompatibility, cytotoxicity, J. Comp. Compd. 2 (2020) 110-114. https://doi.org/10.29252/jcc.2.3.1.

[120] B.S. Bolu, E.M. Gecici, R. Sanyal, Combretastatin A-4 conjugated antiangiogenic micellar drug delivery systems using dendron-polymer conjugates, Mol. Pharmaceutics. 13 (2016) 14821490. https://doi.org/10.1021/acs.molpharmaceut.5b00931.

[121] W.C. Carlyle, J.B. McClain, A.R. Tzafriri, L. Bailey, et al., Enhanced drug delivery capabilities from stents coated with absorbable polymer and crystalline drug, J. Control Release. 162 (2012) 561-567. https://doi.org/10.1016/j.jconrel.2012.07.004.

[122] Y. Zhang, J. Zhou, C. Yang, et al., Folic acid-targeted disulfidebased cross-linking micelle for enhanced drug encapsulation stability and site-specific drug delivery against tumors, Int. J. Nanomedicine. 11 (2015) 1119-1130. https://doi.org/10.2147/IJN.S101649.

[123] H. Tu, Y. Lu, Y. Wu, J. Tian, et al., Fabrication of rectoritecontained nanoparticles for drug delivery with a green and one-step synthesis method, Int. J. Pharm. 493 (2015) 426-433. https://doi.org/10.1016/j.ijpharm.2015.07.063.

[124] P.V. Asharani, Y.L. Wu, Z. Gong, S. Valiyaveettil, Toxicity of silver nanoparticles in zebrafish models, Nanotechnol. 19 (2008) 255102. https://doi.org/10.1088/0957-4484/19/25/255102.

[125] Z.-Y. Zhang, H.-M. Xiong, Photoluminescent ZnO nanoparticles and their biological applications, Mater. 8 (2015) 3101-3127. https://doi.org/10.3390/ma8063101.

[126] L. Bazli, S. Eskandarinezhad, N. Kakur, V. Ramachandran, et al., Electrical properties of polymer blend composites based on Silicone rubber/EPDM/clay for high voltage insulators, J. Comp. Compd. 3 (2021) 18-24. https://doi.org/10.52547/jcc.3.1.3.

[127] A. Abuchenari, H. Ghazanfari, M. Siavashi, M. Sabetzadeh, et al., A review on development and application of self-healing thermal barrier composite coatings, J. Comp. Compd. 2 (2020) 147-154. https://doi.org/10.29252/jcc.2.3.6.

[128] F. Barragh Jam, H. Bangi Houri, M. Ferdosi, Characterization of TiB2 reinforced aluminum matrix composite synthesized by in situ stir casting method, J. Comp. Compd. 2 (2020) 163-170. https://doi.org/10.29252/jcc.2.4.1

[129] M.S. Roberts, M.J. Roberts, T.A. Robertson, et al., In vitro and in vivo imaging of xenobiotic transport in human skin and in the rat liver, J. biophotonics, 1 (2008) 478-493. https://doi.org/10.1002/jbio.200810058.

[130] A.V. Zvyagin, X. Zhao, A. Gierden, et al., Imaging of zinc oxide nanoparticle penetration in human skin in vitro and in vivo, $\mathrm{J}$. Biomed. Opt. 13 (2008) 064031. https://doi.org/10.1117/1.3041492.

[131] K.K. Jain, Applications of nanobiotechnology in clinical diagnostics, Clin. Chem. 53 (2007) 2002-2009. https://doi.org/10.1373/clinchem.2007.090795.

[132] F. Sharifianjazi, A. Jafari Rad, A. Bakhtiari, et al., Biosensors and nanotechnology for cancer diagnosis (lung and bronchus, breast, prostate, and colon): A systematic review, Biomed. Mater. 17 (2021) 012002. https://doi.org/10.1088/1748-605X/ac41fd.

[133] R. Devi, M. Thakur, P.C. Pundir, Construction and application of an amperometric xanthine biosensor based on zinc oxide nanoparticles-polypyrrole composite film, Biosens. Bioelectron. 26 (2011) 3420-3426. https://doi.org/10.1016/j.bios.2011.01.014.

[134] X. Ren, D. Chen, X. Meng, et al., Zinc oxide nanoparticles/glucose oxidase photoelectrochemical system for the fabrication of biosensor, J. Colloid Interface Sci. 334 (2009) 183-187. https://doi.org/10.1016/j.jcis.2009.02.043.
[135] H. Zhang, B. Chen, H. Jiang, C. Wang, et al., A strategy for $\mathrm{ZnO}$ nanorod mediated multi-mode cancer treatment, Biomaterials. 32 (2011) 1906-1914. https://doi.org/10.1016/j.biomaterials.2010.11.027.

[136] R. Khan, A. Kaushik, P.R. Solanki, A.A. Ansari, et al., Zinc oxide nanoparticles-chitosan composite film for cholesterol biosensor. Anal. Chim. Acta. 616 (2008) 207-213. https://doi.org/10.1016/j.aca.2008.04.010.

[137] M.F. Khan, A.H. Ansari, M. Hameedullah, E. Ahmad, et al., Sol-gel synthesis of thorn-like $\mathrm{ZnO}$ nanoparticles endorsing mechanical stirring effect and their antimicrobial activities: Potential role as nano-antibiotics, Sci. Rep. 6 (2016) 27689. https://doi.org/10.1038/srep27689.

[138] S. Pal, S. Bhand, Zinc oxide nanoparticle-enhanced ultrasensitive chemiluminescence immunoassay for the carcinoma embryonic antigen, Microchim Acta. 182 (2015) 1643-1651. https://doi.org/10.1007/s00604-015-1489-5.

[139] P.K. Pandey, P.H. Kass, M.L. Soupir, et. al., Contamination of water resources by pathogenic bacteria, Amb Express. 4 (2014) 51 https://doi.org/10.1186/s13568-014-0051-x.

[140] M. Vajdi, F. Sadegh Moghanlou, F. Sharifianjazi, M. Shahedi Asl, M. Shokouhimehr, A review on the Comsol Multiphysics studies of heat transfer in advanced ceramics, J. Comp. Compd. 2 (2020) 35-43. https://doi.org/10.29252/jcc.2.1.5.

[141] M. Pagliaro, R. Ciriminna, M. Yusuf, et al., Application of nanocellulose composites in the environmental engineering as a catalyst, flocculants, and energy storages: A review, J. Comp. Compd. 3 (2021) 114-128. https://doi.org/10.52547/jcc.3.2.5.

[142] S. Eskandarinezhad, R. Khosravi, M. Amarzadeh, et al., Application of different Nanocatalysts in industrial effluent treatment: A review, J. Comp Compd. 3 (2021) 43-56. https://doi.org/10.52547/jcc.3.1.5.

[143] S. Sarwar, S. Chakraborti, S. Bera, et al., The antimicrobial activity of $\mathrm{ZnO}$ nanoparticles against Vibrio cholerae: Variation in response depends on biotype. Nanomed.: Nanotechnol. Biol. Med. 12 (2016) 1499-1509. https://doi.org/10.1016/j.nano.2016.02.006.

[144] A. Kazemzadeh, H. Kazemzadeh, Determination of $\mathrm{Hg} 2+$ by diphenylcarbazone compound in polymer film, J. Comp. Compd. 1 (2019) 27-30. https://doi.org/10.29252/jcc.1.1.5.

[145] F. Sharifianjazi, A. Esmaeilkhanian, L. Bazli, S. Eskandarinezhad, et al., A review on recent advances in dry reforming of methane over Ni-and Co-based nanocatalysts, Int. J. Hydrog. Energy. (2021). https://doi.org/10.1016/j.ijhydene.2021.11.172.

[146] A. Hakamy, Influence of $\mathrm{SiO} 2$ nanoparticles on the microstructure, mechanical properties, and thermal stability of Portland cement nanocomposites, J. Taibah Univ. Sci.15 (2021) 909917. https://doi.org/10.1080/16583655.2021.2011594.

[147] K.K. Maniam, S. Paul, Progress in novel electrodeposited bond coats for thermal barrier coating systems, Mater. 14 (2021) 4214. https://doi.org/10.3390/ma14154214.

[148] L. Saei Fard, N. Sadat Peighambardoust, H. Won Jang, A. Dehghan, et al., The rechargeable aluminum-ion battery with different composite cathodes: A review, J. Comp. Compd. 2 (2020) 138-146. https://doi.org/10.29252/jcc.2.3.5.

[149] M. Amiri, S. Padervand, V. Tavakoli Targhi, S.M. Mousavi Khoei, Investigation of aluminum oxide coatings created by electrolytic plasma method in different potential regimes, J. Comp. Compd. 2 (2020) 115-122. https://doi.org/10.29252/jcc.2.3.2.

[150] L.K. Foong, Z. Lyu, Sintering and mechanical behavior of SiC and WC co-added TiC-based composites densified by hot-pressing, Cera. Int. 47 (2021) 6479-6486. https://doi.org/10.1016/j.ceramint.2020.10.231.

[151] Y. Yang, X.W. Sun, B.K. Tay. et al., A p-n homojunction ZnO nanorod light-emitting diode formed by As ion implantation, Appl. Phys. Lett. 93 (2008) 253107. https://doi.org/10.1063/1.3054639. 
[152] S. Chu, G. Wang, W. Zhou, et al., Electrically pumped waveguide lasing from $\mathrm{ZnO}$ nanowires, Nat. Nanotechnol.6 (2011) 506-510. https://doi.org/10.1038/nnano.2011.97.

[153] M.A. Rahman, J.A. Scott, A. Gentle, et al., A facile method for bright, colour-tunable light-emitting diodes based on Ga-doped $\mathrm{ZnO}$ nanorods, Nanotechnol. 29 (2018) 425707. https://doi.org/10.1088/1361-6528/aad7d2.

[154] W.Z. Liu, H.Y. Xu, J.G. Ma, et al., Effect of oxygen-related surface adsorption on the efficiency and stability of $\mathrm{ZnO}$ nanorod array ultraviolet light-emitting diodes, Appl. Phys. Lett.100 (2012) 203101. https://doi.org/10.1063/1.4717714.

[155] G. Singh, E.M. Joyce, J. Beddow, T. James Mason, Evaluation of antibacterial activity of $\mathrm{ZnO}$ nanoparticles coated sonochemically onto textile fabrics, J. Microbiol. Biotechnol. 2 (2012) 106-120.

[156] E.V. Lobiak, E.V. Shlyakhova, L.G. Bulusheva, P.E. Plyusnin, et al. Ni-Mo and Co-Mo alloy nanoparticles for catalytic chemical vapor deposition synthesis of carbon nanotubes, J. Alloys Compd. 621 (2015) 351-356. https://doi.org/10.1016/j.jallcom.2014.09.220.

[157] Y. Zamani, A. Zareein, L. Bazli, R. NasrAzadani, et al., Nanodiamond-containing composites for tissue scaffolds and surgical implants: A review, J. Comp. Compd. 2 (2020) 215-227. https://doi.org/10.29252/jcc.2.4.6.

[158] M. Bazli, L. Bazli, R. Rahmani, S. Mansoor, et al., Concrete filled FRP-PVC tubular columns used in the construction sector: A review, J. Comp. Compd. 2 (2020) 155-162. https://doi.org/10.29252/jcc.2.3.7.

[159] J.N. Hasnidawani, H.N. Azlina, H. Norita, N.N. Bonnia, et al., Synthesis of $\mathrm{ZnO}$ nanostructures using sol-gel method, Procedia Chem. 19 (2016) 211-216. https://doi.org/10.1016/j.proche.2016.03.095.

[160] V.-S. Mănoiu, A. Aloman, Obtaining silver nanoparticles by sonochemical methods, U.P.B. Sci. Bull., Series B. 72 (2010) 179186. 